\title{
Assessment of genetic diversity of tomato genotypes by using molecular markers
}

\author{
Rizwan Taj Khan ${ }^{1 *}$, Syed Rizwan Abbas ${ }^{2}$, Syed Dilnawaz Ahmed \\ Gerdezi $^{3}$, Ghazala Javed ${ }^{1}$ and Ansar Mehmood ${ }^{4}$ \\ 1. Department of Botany, University of Azad Jammu and Kashmir, Muzaffarabad, Azad Kashmir-Pakistan \\ 2. Department of biological sciences, Hunza Campus, Karakoram international university, Gilgit-Pakistan \\ 3. University of Kotli Azad Kashmir-Pakistan \\ 4. Department of Botany, University of Poonch, Rawalakot-Pakistan \\ *Corresponding author's email: drrizwantajkhan@gmail.com
}

Citation

Rizwan Taj Khan, Syed Rizwan Abbas, Syed Dilnawaz Ahmed Gerdezi, Ghazala Javed and Ansar Mehmood. Assessment of genetic diversity of tomato genotypes by using molecular markers. Pure and Applied Biology. Vol. 9, Issue 2, pp1532-1540. http://dx.doi.org/10.19045/bspab.2020.90160

\begin{tabular}{llll}
\hline \hline Received: 18/11/2019 & Revised: 30/01/2020 & Accepted: 08/02/2020 & Online First: 16/03/2020 \\
\hline \hline
\end{tabular}

\section{Abstract}

The natural phenotypic variations present in the cultivated plants can be linked to the molecular polymorphism by association genetics. The present study was aimed to screen the drought tolerant genotypes by morphological, biochemical and measuring the genetic diversity by using Simple Sequence Repeats (SSR) markers. An experiment consisting of 26 genotypes was conducted in the laboratory of Biotechnology University of Azad Jammu and Kashmir Muzaffarabad, Pakistan. Seeds were grown in pots and 4 weeks older leaves were used for DNA extraction. Twenty-six genotypes of Tomato (Lycopersicon esculentum Mill.) were fingerprinted with 30 (SSR) markers by using Polymerase Chain Reaction (PCR) technique. Nei's genetic distances for SSR markers, data was calculated and relation matrix between genotypes was shown graphically in the form of a dendrogram. All the 26 tomato genotypes showed genetic distances of $1.0-2.20$ between them. A smallest genetic distance 0.2 was recorded between genotypes G6-17909, G5-17904 and G21006234, G12-0852, G7- 88572 G32 -19233, G28-17903, G12-17806 indicating closer relationship between the genotypes. The most distant accessions were G7-1059 and G45-19212. The marker (SSR) based fingerprints will assist for their future potential in crop improvement.

Keywords: Analysis; Cluster; Diversity; Genetic; SSR; Tomatoes

\section{Introduction}

The tomato (Lycopersicon esculentum Mill) was started from Latin America, it is the second most significant vegetable crop cultivated all over the world. It gives both pro-vitamin $\mathrm{A}$ and vitamin $\mathrm{C}$ to the human diet and providing high economic value to producers and breeding industries in many countries [1]. The tomato belongs to the family Solanacea which includes at least 100 genera and 2500 species including important agronomic plants like potato, eggplant, pepper and tobacco [2]. The tomato genetic materials are important resources for breeding purposes and biotechnology and their relationship studies have potential value in tomato industry. The knowledge of genetic studies has an important impact on the conservation and breeding. There are various approaches to measure the genetic variations which include pedigree information, morphological and molecular techniques. 
One of the most important techniques in this background is the polymerase chain reaction (PCR) by which the traces of DNA can be identified [3, 4]. Morphological characters cannot be used to measure the genotypic differences because these can be changed by the environment [5]. In comparison to this, the molecular markers such as amplified fragment length polymorphism (AFLP), random amplified polymorphic DNA (RFLP), random amplified polymorphic DNA (RAPD), single nucleotide polymorphism (SNP), and simple sequence repeats (SSR) can be effectively used for a variety identification because they are independent of environmental factors $[6,7]$. The SSR markers are the important among all the available marker system for variety identification because of the properties of genetic codominance, high reproducibility and multiallelic variation [8]. The DNA molecular markers can be used to study the genetic diversity and the variations in the genus Solanum and for selecting the tomato [1, 9-15].

Simple sequence repeats (SSRs), are also recognized as microsatellites, bear good results in molecular research because of the properties like having high reproducibility, multi-allelic nature, co-dominant inheritance, high abundance and wide genome coverage $[16,17]$. Microsatellites are widely used in the studies of different plant species. Various studies have shown the efficacy of SSR markers for assessing the genetic diversity in the genus Solanum [18]. There are many reports signifying the practicality of microsatellite markers for calculating the genetic variability in a wider taxonomic range [19].

The present study has been conducted to measure the genetic diversity within different tomato genotypes by using molecular markers and development of phylogentic tree, by using bio informatics tools. Estimation of genetic diversity and relationships between germplasm collections are important for facilitating efficient germplasm collection, evaluation and utilization [20].

\section{Materials and methods}

Twenty-six (Table 1) tomato genotypes were used for the finger printing at DNA level by using 30 SSR primers in this study. The seeds were sown in small pots and at the seedling stage leaves were collected from five plants of each genotype for DNA isolation.

Table 1. List of genotypes

\begin{tabular}{|c|c|c|c|c|c|}
\hline G7-10593, & G11-17895 & G12- 17880 & G26- 19293 & G28- 17903 & G31-19289 \\
\hline G32-19223 & G37-19895 & G38-19896 & G49-19889 & G44-19911 & G43-19907 \\
\hline G46-19913 & G47-6231 & G8-19219 & G2-006233 & G3-10574 & G4Lo-4360 \\
\hline G5-017904 & G6-017909 & G7-88507 & G11-3715 & G12-08527 & G21-006234 \\
\hline G31-006234 & G45-9219 & & & & \\
\hline
\end{tabular}

\section{DNA extraction}

DNA extraction was carried out by using the Abbas DNA extraction method [21] from the leaves of tomato. The plants were grown in the green house. After buds growth, the young leaves were used for DNA extraction. The PEG was applied to mash the material and the cell wall was broken without damaging DNA.

\section{Reagents}

An extraction buffer consisting of $1 \%$ PEG (6000), 1MTris ( $\mathrm{pH} 8.0$ ), 0.5M EDTA (pH 8.0), $10 \%$ SDS and $4 \mathrm{M} \mathrm{NaCl}$ were prepared. 2. Chloroform: ISO-amyl-alcohol (24:1) and $100 \%$ and $75 \%$ ethanol. 3. TBE buffer consisting of $5.4 \%$ Trizma, $2.72 \%$ Boric acid and $2 \mathrm{ml} \mathrm{0.5M} \mathrm{EDTA.}$ 


\section{Method}

Plant material (1g) weighed and ground in a buffer to make slurry. The slurry was poured in eppendorff tube and kept at $65 \mathrm{oC}$ for 30 minutes in an oven. Chloroform and isoamyl alcohol in the ratio of 24:1 was mixed with the extract at room temperature in a shaker for 3 minutes and the samples kept undisturbed for 5 minutes. The contents were centrifuged at 13,000 rpm for 10 minutes. Supernatant was collected in a new eppendorff tube and was precipitated in $95 \%$ ethanol with gentle mixing and was kept for 15 minutes at room temperature. It was centrifuged at 13,000 rpm for 5 minutes, and the supernatant was discarded. The pallet was Wash with 50\%, 70\% and absolute ethanol. The DNA pellet was dissolved and stored at $-80 \mathrm{C}$

The insoluble materials were separated by centrifugation to purify the DNA while soluble proteins and other materials were separated by the addition of Iso-chloform and centrifugation. DNA was precipitated from the solution and washed carefully with ethanol to take away contaminating substituent. The purified genomic DNA was stored in TE buffer. This method has provided intact DNA from plant tissue. The whole genomic DNA of 26 genotypes was successfully extracted using the above described method. The DNA quality was rather fine as observed by running and visualizing on $0.8 \%$ agarose gel as well as spectrophotometrically.

\section{Estimation of DNA concentration}

The amount and quality of complete genomic DNA of 26 genotypes was determined after comparing them with a DNA ladder of low mass and visualized at $0.8 \%$ agarose gel prepared in O.5xTE buffer with ethidium bromide. Automated spectrophotometer (Nano-drop equipment) was also used to quantify the genomic DNA which calculates absorbance at $260 \mathrm{~nm}$. The precise concentration of DNA was obtained by the use of this equipment. It was diluted with standard deionized double distilled water and small quantity of sample $(1 \mu \mathrm{L})$ was used for the measurement.

\section{Conditions optimization for SSR analysis}

30 SSR primers (Table 2) were used for the diversity analysis. SSR sequences are present in whole genome and are highly polymorphic, co-dominant and definite DNA sequences are required as primer. The both reverse and forward primers are required for PCR reactions of SSRs which joins at both 5 and $3^{\prime}$ ends of the genomic DNA. These fragments are isolated on gels like polyacrylamide and agarose. Different concentrations of $\mathrm{MgCl} 2$, Taq DNA polymerase, dNTPs, DNA and annealing temperature were optimized.

\section{Table 2. List of SSR primers}

\begin{tabular}{|c|}
\hline SSR Primers for Diversity in Tomato \\
\hline 1= SSR 9 F= CCCTTTGCAAGTTCTTCTTCA \\
\hline R= TTCATGAGCCAACATAGGAGG \\
\hline 2= SSR13 F= GGGTCACATACATACACTCATACTAAGGA \\
\hline R=CAAATCGCGACATGTGTAAGA \\
\hline 3 =SSR19 F= CCGTTACCTTGGTCCATCAC \\
\hline R=GGGAGATGCCACATCACATA \\
\hline 4 =SSR20 F $=$ GAGGACGACAACAACAACGA \\
\hline R GACATGCCACTTAGATCCACAA \\
\hline 5 =SSR22 F=GATCGGCAGTAGGTGCTCTC \\
\hline R=CAAGAAACACCCATATCCGC \\
\hline 6=SSR26= F= CGCCTATCGATACCACCACT \\
\hline $\mathrm{R}=$ ATTGATCCGTTTGGTTCTGC \\
\hline
\end{tabular}




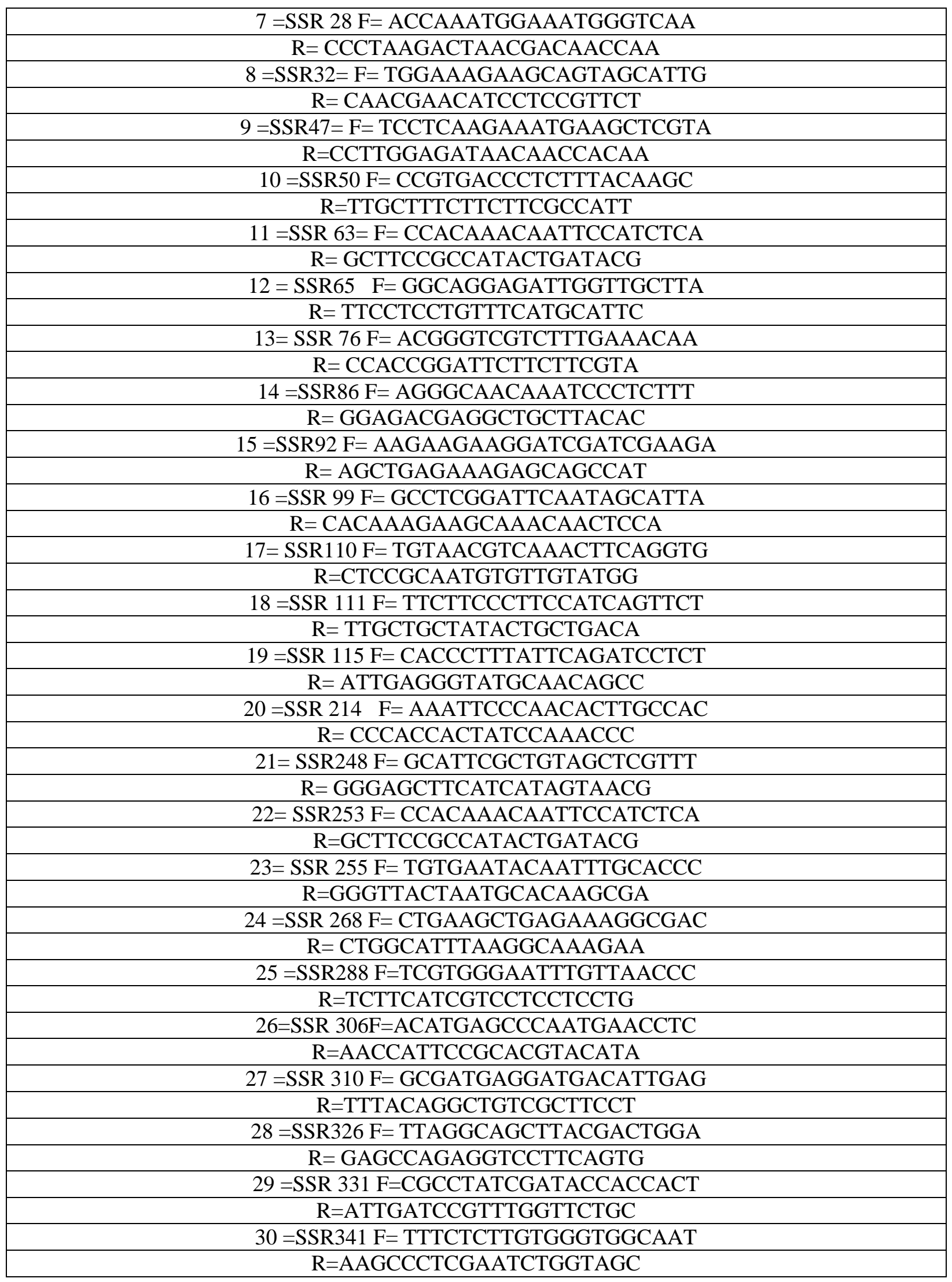




\section{Results and discussion}

DNA polymorphism between tomatos varieties was investigated by using SSR markers based on the allele frequency at each locus examined (Fig. 1, 2). Nei's genetic distances for SSR markers was calculated and relation matrix between genotypes was shown graphically in the form of a dendrogram (Fig. 3). All 26 tomato genotypes showed genetic distances of 1.0 -2.20 between them. A smallest genetic distance was recorded 0.2 between genotypes G6-17909, G5-17904 and G21006234, G12-0852, G7- 88572 G32 -19233, G28-17903, G12-17806 indicating closer relationship between the genotypes. The most distant accessions were G7-1059 and G45-19212. All the 26 tomato genotypes were grouped into 2 main clusters and 4 sub clusters. Genetic diversity can be calculated both by molecular and morphological markers (Fig. 1, 2). The morphological attributes provide a simple technique for quantification of genetic variation by assessing the performance under different environmental conditions $[20,21]$. The studies of morphological traits take long time and the environment and developmental stages can influence the plant stages [22-25]. On the other hand the molecular markers are independent of environment and higher intensities of polymorphism. However the high morphological variations are not always reflected at molecular level [26].

Cluster 1 consists of 16 genotypes and cluster 2 contains 10 genotypes. Cluster 1 was subdivided into 3 sub-groups and cluster II was subdivided into 2 sub clusters. The cluster 1 consists of genotypes, G45 19212, G31 006234, G2106234, G12 08527, G11 Lo 3715, G7 88527, G6 017909, G50 17909, G4 lo 4360, G3 10754, G200623. The cluster II consists of G40 19898, G38 19896, G37 19895, G33 19293, G31 19289, G 2817903. The genotype G 710593 showed a different arrangement in cluster analysis. So the molecular studies also grouped the genotypes into a cluster pattern in which many genotypes fall. The genotypes G45 19212 and G31 006234 produced same number of branches at highest level of poly ethylene glycol and were also grouped together in the same cluster. Similarly other genotypes grouped together in a cluster produced same results for different morphological characters. The cultivated tomato generally shows lower genetic diversity due to the presence of population bottlenecks during the domestication and production of new varieties [27].

Based on the above molecular marker based diversity analysis we can conclude that this study confirms the efficiency of the employed SSR markers in assessing and discriminating tomato genotypes. Such studies should be useful both for identification of duplicate accessions and establishment of core collection in the gene banks, as well as for sustainable conservation of the genotypes collected. Accurate molecular depiction of conserved collections will allow for more proficient management and utilization of genotypes in the breeding programs. Although the cultivated tomato (Lycopersicon esculentum) differed significantly but it behaves monomorphically mostly at molecular level. The molecular markers which are polymorphic in nature have difficulty in identification of this narrow diversity. However some of the polymorphic microsatellite markers which are developed from the database have been used efficiently to genotype the different tomato accessions and cultivars [1]. 


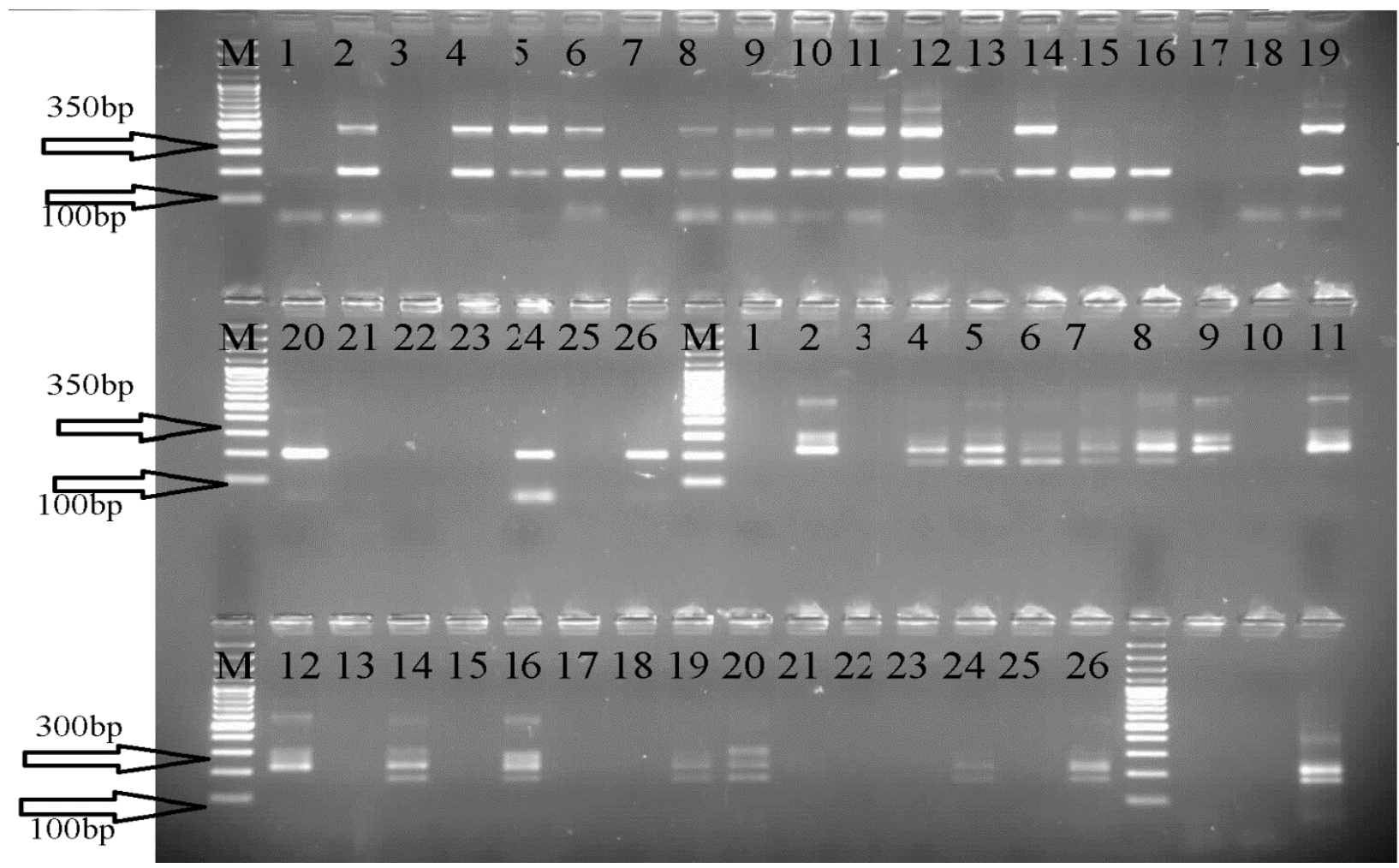

Figure 1. Gel electrophoreses of 26 genotypes of tomatoes for genetic diversity
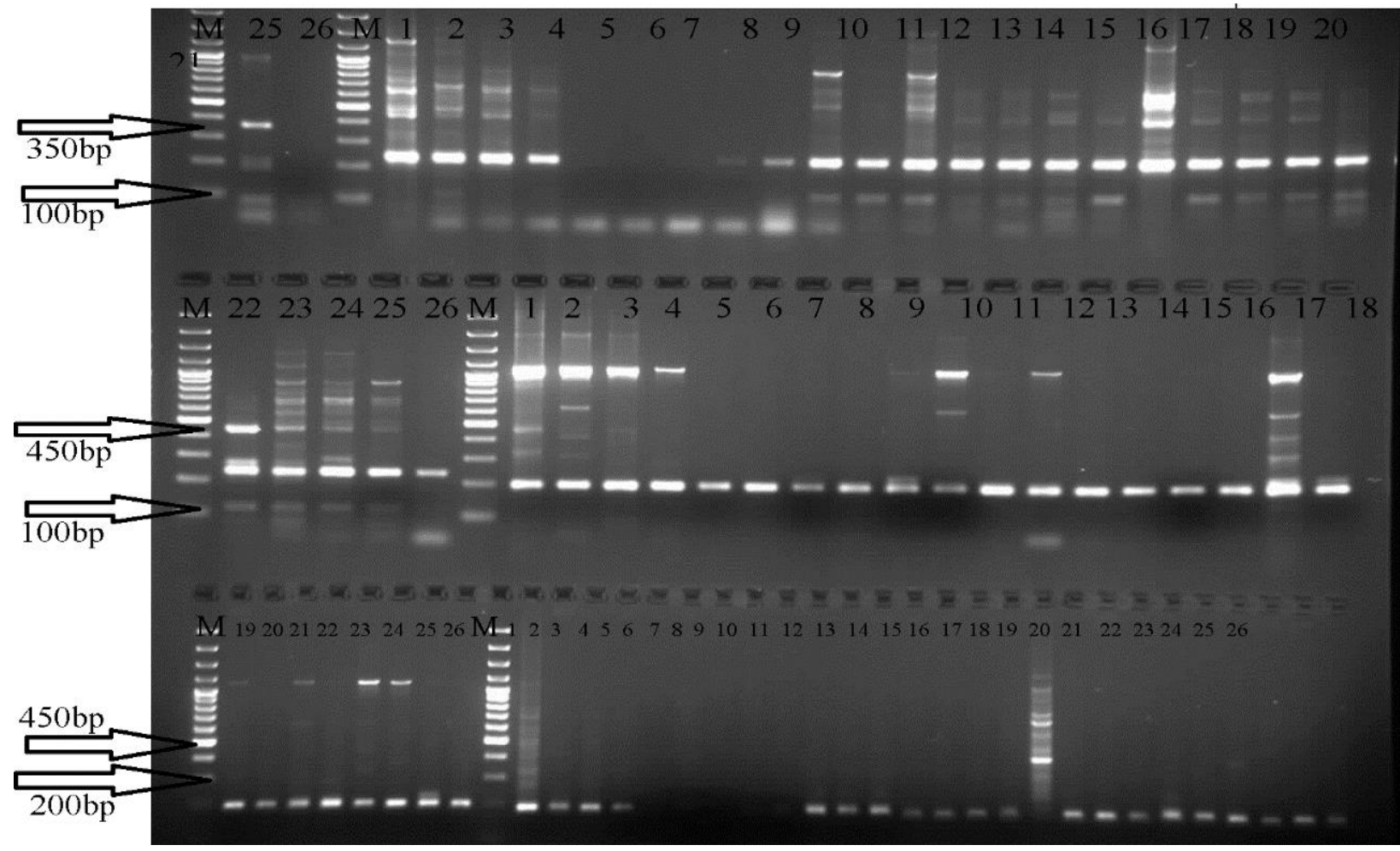

Figure 2. Gel electrophoreses of 26 genotypes of tomatoes for genetic diversity 
Denderogram of 26 Tomato genotypes

Euclidean distances

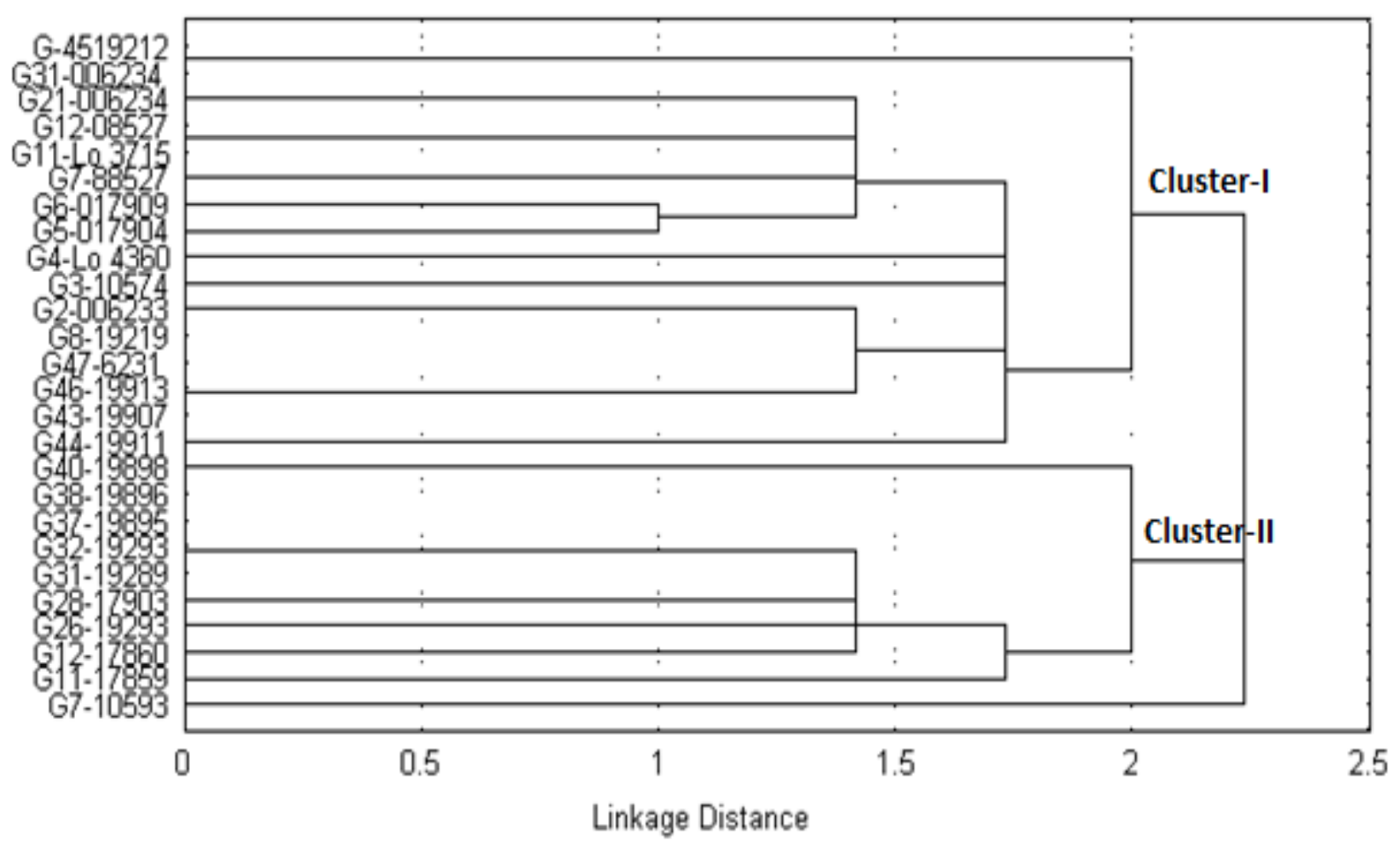

Figure 3. Denderogram of linkage distance for 26 genotypes of tomatoes

\section{Conclusion}

The present study showed a genetic diversity among some selected 26 genotypes with 30 SSR primers. The genotypes were also analyzed under drought stress for morphological and biochemical characteristics. It can be further investigated by increasing the number of primers and genotypes of Pakistan and Azad Kashmir.

\section{Authors' contributions}

Conceived and designed the experiments: RT Khan, Performed the experiments: RT Khan, Analyzed the data: SR Abbas \& A Mehmood, Contributed materials/ analysis/ tools: SDA Gerdezi, Wrote the paper: RT Khan \& G Javed.

\section{References}

1. He C, Poysa V \& Yu K (2003). Development and characterization of simple sequence repeat (SSR) markers and their use in determining relationships among Lycopersicon esculentum cultivars. Theor Appl Genet 106: 363-373.

2. Olmstead RG, Bohs L, Migid HA \& Santiago-Valentin E (2008). A molecular phylogeny of the Solanaceae. Taxon 57: 1159-1181.

3. Marmiroli N, Peano C \& Maestri E (2003). Advanced PCR techniques in identifying food components, pp 3-33 in $M$ Lees, Ed. Food authenticity and traceability. Wood head Publishing, Cambridge, UK.

4. Marmiroli N, Maestri E, Pafundo S \& Vietina M (2009). Molecular traceability of olive oil: From plant genomics to food genomics, pp 157-172 in L. Berti and J. Maury, eds. Advances In Olive Resources. Trans world Research Network, Trivandrum, India. 
5. Agrimonti C, Vietina M, Pafundo S \& Marmiroli N (2011). The use of food genomics to ensure the traceability of olive oil. Trends Food Sci Tech 22: 237244.

6. Cooke RJ (1995). Varietal identification of crop plants, pp 33-63 in J Skerritt and R Appels, Eds. New Diagnostics in Crop Sciences. CAB International, Wallingford.

7. Lee LS \& Henry RJ. 2001. Commercial applications of plant genotyping, pp 265-273 in RJ Henry, Ed. Plant genotyping: the DNA fingerprinting of plants, CABI Publishing, Wallingford, Oxon.

8. Sim SC, Robbins MD, Chilcott C, Zhu T \& Francis DM (2009). Oligonucleotide array discovery of polymorphisms in cultivated tomato (Solanum lycopersicum L.) reveals patterns of SNP variation associated with breeding. $B M C$ Genomics 10: 466.

9. Powell W, Machray GC \& Provan J (1996). Polymorphism revealed by simple sequence repeats. Trends Plant Sci 1:215-222.

10. Smulders M, Bredemeijer G, RusKortekaas W, Arens P \& Vosman B (1997). Use of short microsatellites from database sequences to generate polymorphisms among Lycopersicon esculentum cultivars and accessions of other Lycopersicon species. Theor and Appl Genet 94(2): 264-272.

11. Bredemeijer M, Cooke J, Ganal W \& Peeters R (2002). Construction and testing of a microsatellite database containing more than 500 tomato varieties. Theor Appl Genet 105: 10191026.

12. Frary AY, Xu J, Liu S, Mitchell E \& Tanksley $S$ (2005). Development of a set of PCR-based anchor markers encompassing the tomato genome and evaluation of their usefulness for genetics and breeding experiments. Theor Appl Genet 111: 291-312.

13. Garc 1a-Mart 1nez SL, Andreani M, Garc 1a-Gusano F \& Ruiz JJ (2006). Evaluation of amplified fragment length polymorphism and simple sequence repeats for tomato germplasm fingerprinting: utility for grouping closely related traditional cultivars. Genome 49: 648-656.

14. Song LQ, Fu TD, Tu JX, Ma CZ \& Yang GS (2006). Molecular validation of multiple allele inheritance for dominant genic male sterility gene in Brassica napus L. Theor Appl Genet 113: 55-62.

15. Kwon YS, Park SG \& Yi SI (2009). Assessment of genetic variation among commercial tomato (Solanum lycopersicum L) varieties using SSR markers and morphological characteristics. Genes \& Genomics 31(1): 1-10.

16. Turci M, Savo ML, Sardaro G, Visioli E, Maestri M \& Marmiroli N (2010). Evaluation of DNA extraction procedures for traceability of various tomato products. Food Control 21: 143149.

17. Caramante M, Corrado G, Monti LM \& Rao R (2011). Simple Sequence Repeats are able to trace tomato cultivars in tomato food chains. Food Control 22: 549-554.

18. Powell W, Machray GC \& Provan J (1996). Polymorphism revealed by simple sequence repeats. Trends Plant Sci 1: 215-222.

19. Benor $S$, Zhang M, Wang $Z$ \& Zhang $H$ (2008) Assessment of genetic variation in tomato (Solanum lycopersicum L.) inbred lines using SSR molecular markers. J Genet and Genom 35(6): 373379.

20. García-Martínez S, Andreani L, GarciaGusano M, Geuna F \& Ruiz JJ (2006). Evaluation of amplified fragment length 
polymorphism and simple sequence repeats for tomato germplasm fingerprinting: utility for grouping closely related traditional cultivars. Genome 49(6): 648-656.

21. Fufa H, Baenziger PS, Beecher I, Dweikat V, Graybosch RA \& Eskridge KM (2005). Comparison of phenotypic and molecular marker-based classifications of hard red winter wheat cultivars. Euphytica 145: 133-146.

22. Abbas SR, Gardazi SDA, Sabir SM, Shah AH, Abbas MR \& Batool A (2013). ABBAS" DNA Extraction Method from plants. Int J Sci \& Engg Res 4(7): 992994.

23. Shuaib M, Alam Z, Zahir A, Waqar A, Taufiq A \& Ikhtiar K (2007). Characterization of wheat varieties by seed storage protein electrophoresis. Afr J Biotechnol 6: 497- 500.
24. Tatineni V, Cantrell RG \& Davis DD (1996). Genetic diversity in elite cotton germplasm determined by morphological characteristics and RAPDs. Crop Sci 36: 186-192.

25. Van Beuningen LT \& Busch RH (1997). Genetic diversity among North American spring wheat cultivars: III. Cluster analysis based on quantitative morphological traits. Crop Sci 37: 981988.

26. Wang RS, Li DD, Yang LT, Li LZ, Fan FX \& Li WJ (2006). Analysis of genetic diversity based on SSR and morphological markers among tomato cultivars. J Trop Subtrop Bot 14(2): 120125.

27. Rick CM (1976). Tomato, Lycopersicon esculentum (Solanaceae), pp 268-273 in NW Simmonds, Ed. Evolution of crop plants. Longman Group, London. 